University of Wollongong

Research Online

Faculty of Commerce - Papers (Archive)

Faculty of Business and Law

$1-1-2000$

\title{
Some recent developments in the evaluation of university research outcomes in the United Kingdom
}

Samuel Garrett-Jones

University of Wollongong, sgarrett@uow.edu.au

David K. Aylward

daylward@uow.edu.au

Follow this and additional works at: https://ro.uow.edu.au/commpapers

Part of the Business Commons, and the Social and Behavioral Sciences Commons

\section{Recommended Citation}

Garrett-Jones, Samuel and Aylward, David K.: Some recent developments in the evaluation of university research outcomes in the United Kingdom 2000, 69-75.

https://ro.uow.edu.au/commpapers/825

Research Online is the open access institutional repository for the University of Wollongong. For further information contact the UOW Library: research-pubs@uow.edu.au 


\title{
Some recent developments in the evaluation of university research outcomes in the United Kingdom
}

\author{
Abstract \\ Three specific recent developments in the evaluation of UK university research-the Research \\ Assessment Exercise, the common performance indicators for the research councils, and the 'evaluation \\ portfolio' of the Economic and Social Research Council - are described, and how they work in practice is \\ examined. As in other countries, we find some tension between the criteria of excellence and \\ socioeconomic benefit in valuing research outcomes. Driven by government policy, the primacy of peer \\ evaluation based on publications is being strongly augmented by methods and performance measures \\ that attempt to capture the broader benefits and impacts of academic research within the context of \\ agency and national planning.
}

\section{Keywords}

united, kingdom, recent, university, developments, outcomes, research, evaluation

\section{Disciplines}

Business | Social and Behavioral Sciences

\section{Publication Details}

Garrett-Jones, SE, and Aylward, DK, Some recent developments in the evaluation of university research outcomes in the United Kingdom, Research Evaluation, 8, 2000, 69-75. 


\section{academic research}

\section{Some recent developments in the evaluation of university research outcomes in the United Kingdom}

\section{Sam Garrett-Jones and David Aylward}

Three specific recent developments in the evaluation of UK university research - the Research Assessment Exercise, the common performance indicators for the research councils, and the 'evaluation portfolio' of the Economic and Social Research Council - are described, and how they work in practice is examined. As in other countries, we find some tension between the criteria of excellence and socioeconomic benefit in valuing research outcomes. Driven by government policy, the primacy of peer evaluation based on publications is being strongly augmented by methods and performance measures that attempt to capture the broader benefits and impacts of academic research within the context of agency and national planning.
Associate Professor Sam Garrett-Jones is Deputy Director and $\mathrm{Mr}$ David Aylward is Senior Research Assistant, the Centre for Research Policy, Faculty of Commerce, University of Wollongong, Wollongong, NSW 2522, Australia; Tel: 6124221 3256; Fax: +61 24221 3257; E-mail: Sam_Garrett-Jones@uow.edu.au.
This N CONTRAST WITH OTHER contributions to this volume, this paper provides an 'outsider's view' of selected developments in the evaluation of university research in the United Kingdom. We chose to examine three aspects of the recent UK experience that appear particularly relevant to a country like Australia, which has a somewhat similar higher education research funding system, albeit on a smaller scale. These are the evolution of the Research Assessment Exercise (RAE) for block grants to universities, the development of common performance indicators for the UK research councils by the Office of Science and Technology (OST), and the 'evaluation portfolio' assembled by a particular research council, the Economic and Social Research Council (ESRC). On the basis of a select number of interviews with the practitioners and on documentary evidence, we focus on the way these different evaluation mechanisms operate in practice and have evolved in recent years. A comprehensive review of the development of research and technology evaluation practices in Britain more generally is provided by Hills and Dale (1995) and from a government perspective by Barker and Lloyd (1997).

\section{Policy context and driving forces}

It is widely argued that the UK has one of the most advanced research evaluation systems in Europe (Hills and Dale, 1995). The Royal Society's peer-review system has operated for more than 400 years. There is also a relatively longstanding commitment to public 
sector auditing. In recent years, monitoring and evaluation of research has been driven more by a 'value for money' ethos within a static budget (Hills and Dale, 1995). The incoming Labour Government carried out a comprehensive spending review exercise with the prospect of significantly more money for science, and indeed the research funds allocated on the basis of the RAE have increased substantially. However, the agenda for research (and its evaluation) is still set by the previous administration's 1993 White Paper 'Realising Our Potential' (UK Government, 1993), the first such statement on science, engineering and technology policy since the 1960s (Hills and Dale, 1995). While recognising that 'excellence is very important; second rate research is a poor buy' (UK Government, 1993), the White Paper - in common with similar documents from other countries - places strong emphasis on assessing the economic and social relevance and contribution of government funded academic research and its take-up by potential users.

Government funding for university research in the UK is allocated through a 'dual support' arrangement. Block grants for infrastructure, research and teaching activities are provided by the regional Higher Education Funding Councils (HEFC), while six discipline-based research councils ${ }^{1}$ allocate the 'science budget', largely for research projects and postgraduate training. Allocation of the HEFCs' research funds takes into account the results of the periodic RAE. The research councils have a range of procedures in place for evaluating the outputs and impact of the research and research training activities that they fund. The Office of Science and Technology within the Department of Trade and Industry (DTI) has an important coordinating role, especially in relation to research evaluation and performance indicators for government science agencies.

\section{Research assessment by the HEFCs}

The primary purpose of the Research Assessment Exercise is to provide quality rankings for government-funded academic research in the UK. The 1996 RAE, which followed earlier exercises in 1986, 1989 and 1992, was conducted by the Higher Education Funding Councils for England, Scotland and Wales and the Department of Education for Northern Ireland. Each body distributes research funds primarily on the basis of quality judgements by expert panels. The Funding Councils will conduct a further RAE in 2001, broadly similar to the 1996 exercise, in order to produce research quality ratings for the allocation of research funding for the year 2002-03.The RAE is an expensive exercise - costing an estimated $£ 2.25$ million in 1996 for the 69 panels and secretariat, but not including university compliance costs. It is also massive in terms of the funds channelled into university research. The Funding Councils distributed over $£ 680$ million on the basis of the 1996 RAE ratings and have allocated around $£ 5$ billion for distribution in 2002-03. Although not without its critics, the RAE appears entrenched in UK university research evaluation practice and the comprehensive Dearing Report on higher education in 1997 presumed its continuation.

RAE ratings are awarded by 69 subject panels, each comprising about 10 members who are usually distinguished researchers. Panel assessments are based exclusively on written material submitted by institutions. The data include: details of staff whose research is offered for assessment and their selected outputs (maximum four per researcher); additional information concerning research activity in units of assessment (numbers of research students, research grants and contract income); and information concerning the institution's support for research in the particular subject. The unit of assessment corresponds broadly to a university department. This fine level of disaggregation of rating units is an important aspect of the RAE. Panels award ratings on a seven-point scale for the proportion of work in each submission that is judged to reach national or international standards of excellence, applying criteria and working methods appropriate to the subject area. They also collaborate in the assessment of multidisciplinary research and seek external advice as necessary.

The RAE is a good example of what Paul Bourke (1997) calls the 'mass evaluation system'. As Bourke notes, in an analysis of the RAE as an evaluation, funding and policy instrument, the RAE has had the effect of drawing a sharp distinction between those departments and individuals that are 'research active' and those that are not. Indeed, the Dearing Report suggested that departments be allowed to opt out of the RAE altogether. In theory, panels are primarily concerned with making quality judgements based on selective reading of the listed research outputs as well as other evidence of reputation and track record. In practice, as Bourke comments, 'relatively little first order evaluation can occur ... except in the smaller fields'. As a result, 'panels rely heavily on surrogates, of which the most important is ... the evaluation processes of scholarly journals and book publishers' (Bourke, 1997: Chapter 4).

The RAE seems to have established a reputation as a reasonably efficient, credible and disinterested evaluation mechanism. Clearly, there are limitations to the 'mass peer review' it embodies, in addition to those noted by Bourke, such as the strain it puts on the refereeing system, and conservatism within the panels. The Dearing Report recommended greater use of international panel members and an evaluation of the treatment of interdisciplinary research within the RAE ('Dearing Report', 1997: Recommendations 32 and 33). A further common criticism of the RAE is that it leads to unproductive competition between institutions (eg, 'poaching' of researchers) that does not necessarily enhance the overall quality of research within UK universities.

Perhaps the most serious criticism, however, is of the relatively narrow 'reward base' of the RAE, with its emphasis on academic publications. This represents a significant mismatch with the research 
Table 1. Proposals for the evolution of RAE procedures, post 1996

- requiring details of up to four items of research per active researcher;

- using a seven-point scale numbered from $1-5^{*}\left(5^{*}\right.$ being the highest) as with $1996 \mathrm{RAE}$;

- compiling research income data from all sources;

- compiling information on postgraduate activity and research culture and plans;

- allowing submission of work produced over the five-year period between RAEs for all disciplines except the arts and humanities, which will be allowed a seven-year time span;

- all panels to produce written reports confirming their working methods, to be published by the funding councils;

- all panels should provide feedback on each submission for the head of the applicant's institution;

- permitting panel members to serve in only two successive exercises and chairs in a maximum of three (but only twice as chair);

- rolling forward no more than half the membership of any one panel;

- RAE councils to consult panels and other bodies that have successfully engaged peer reviewers on the most appropriate methods of using peer review in the RAE;

- requiring panels to state their criteria and their approach to using specialist advisers;

- allowing panels to establish ad hoc advisory panels to advise on significant bodies of work beyond the expertise of other panels;

- overseeing criteria-setting processes to ensure that all criteria are reasonable, defensible and consistent.

Source: HEFC, 1998

outcomes valued in the mission statements and performance indicators set for the UK research councils, discussed below. These include the promotion of interdisciplinarity as well as the broad socioeconomic impact of research. However, as the ESRC pointed out to us, while the RAE ranking of the department is not specifically taken into account when assessing ESRC project applications the Council's expectation is that the top quality proposals will come from the units ranked more highly on RAE - indeed the top 12 universities take about $50 \%$ of ESRC research funds.

Reform of the RAE. In an attempt to redress such concerns, the HEFCs undertook widespread consultation on the future direction of the RAE during 1998. Steps are being taken to make the process more transparent and to achieve greater consistency across the panels (for example, by publishing 'protocols' in the Dutch sense - see van der Meulen and Rip, this volume). As well as the procedural changes (described in Table 1), the Councils are considering the establishment of a 'roving' panel of experts to ensure comparability and robustness of panel judgements. In addition, there will be established a small number of 'umbrella' groups of panels chairs to ensure consistency of approach and marking standards. Panels will also be required to consult a group of non-UK researchers as referees before the awarding of top rankings.

The Councils are also considering the case for an element of self-assessment. Each unit may submit, along with other requested data, a self-assessment against the rating scale. Alternatively, submitting units may be requested to rate their own performance under key indicators. This element of self-assessment may help both the applicant and the panel members to focus on reported achievements within a possibly diverse department as well as improving the way cases are presented to panels. The Councils are also investigating whether research assessments may include institutional visits as a way of addressing concerns about the undue emphasis placed on disembodied outputs as opposed to research context and research environment.

\section{The OST and performance indicators for the RCs}

The 1993 White Paper set out to introduce effective performance indicators for the research councils. The implementation of this policy has largely been the task of the Office of Science and Technology, created in 1992 and now within the Department of Trade and Industry, which funds the six councils. The White Paper strengthened the coordinating role of OST and also stressed the Office's active role in 'encouraging Departments to develop relevant output measures and performance indicators and to evaluate the success of programmes they commission' within the framework of 'foresight' and other planning measures (UK Government, 1993). Fifteen performance indicators or 'process measures' under five headings were quickly developed by OST for departmental S\&T programs (Hills and Dale, 1995). Indicators were developed in respect of the missions set out for the (then newly reorganised) research councils by the 1993 White Paper. In general, these missions are promotion and support of high quality research and related postgraduate training; meeting the needs of users of research and training; enhancing the UK's industrial competitiveness; and enhancing the UK's quality of life (UK Government, 1993).

By 1998, OST was pressing the councils to go beyond simply listing or counting their 'products' and to come up with true indicators of the quality of their outputs. OST recognised that their 'Mark 1' indicators were not quite right. Draft indicators were developed by the OST in consultation with the research councils (Table 2).

The Councils were reporting against the indicators in Table 2 as this paper was being written. For some of these indicators there is little information available beyond basic statistics. The information collected and used by each research council varies somewhat, partly reflecting their different roles. For example, PPARC measures UK success in providing instrumentation at the European Space Agency, while the Natural Environment Research Council (NERC) records publication of maps. The records of international research collaboration are diverse - the Engineering and Physical Sciences Research Council (EPSRC) reports none, PPARC has UK holders of senior positions in the European nuclear research centre (CERN) and collaborations with the German electron synchrotron (DESY). The other councils have lists of European Union and other international research collaborations.

For research outputs, all councils have annual publication counts. The Medical Research Council 
Table 2. Corporate performance indicators for the Research Councils, 1997-98 (July 1998)

The research objective

- Analysis of published research, eg, high quality papers (output) and citations (impact) in relevant fields (including comparison with leading countries and time series/recent trend analysis).

- Number, type and value of European Union and other international collaborations/partnerships (international standing).

The training objective

- PhD submission and MSc success rates (trained personnel).

- First destination data (broken down by PhD and MSc) on former students and fellows (quality and utility of training)

- Career path tracking of former students and fellows (quality and utility of training).

- Total expenditure and awards (training and research) to each university (selectivity).

- Total expenditure and awards (training and research) to departments rated $1-5^{*}$ in the RAE exercise (selectivity of spending).

The industrial competitiveness and quality of life objectives

- Income from the UK private and public sectors (user perception).

- Numbers and value of Collaborative Awards in Science and Engineering (CASE) and other industrial studentships (eg, Teaching Company Scheme), planned and taken up (industry-focused training).

- Number and value of collaborative (eg, LINK) and co-funded research projects (collaboration with industry). [LINK is a cross-government set of programmes to bridge the science and engineering base and industry.]

- Number of co-publications with industry (collaborations with industry)

- Impact on work programmes of Council response to Foresight priorities (response to opportunities identified by Foresight).

- Mechanisms for capturing and responding to input from the user community (user and non-academic influence on policies and decisions)

\section{The promotion of science objective}

- Interaction with schools (developing awareness).

- Level of spend on public understanding of science (level of resources directed to public understanding of science).

- Spend on public understanding of science activities as a proportion of share of the science budget.

Source: Office of Science and Technology

(MRC) looks at research papers in high quality or highly cited journals, and presents important medical achievements. It also uses information on the exploitation of MRC-funded research through trends in income from intellectual property rights, employment in start-up companies, patent filings and licensing agreements.

In relation to the training outcomes, all research councils have information on postgraduate degree submission rates and first employment destination, but are only now piloting career path tracking for former research students and fellows. PPARC has undertaken surveys of the quality of research training. Some problems of comparability of the financial and scholarship data remain. Expenditure on postgraduate awards from the research councils cannot be compared directly with the 'units of assessment' (academic units) used in the RAE, for example. According to Barker and Lloyd (1997), experience in the UK with surveys on the career paths of postgraduates generally has found the methodologies expensive and of dubious quality.

The research councils reported relatively little information on the broader social and economic impacts of their research. It appears limited to financial information on external and collaborative funding for research and studentships. However, all except ESRC and EPSRC have data on academic co-publications with industry researchers. For the promotion of science objectives the available performance indicators include the numbers of schools involved in particular programs. Overall, the OST performance indicators are primarily ones of activity rather than impact.

OST has been pushing the use of bibliometrics, and this has been picked up by several research councils. For example, the NERC has used citation counts both as an evaluation tool and predictor. The MRC is also starting to use bibliometric indicators as an evaluation and policy tool at a high level of aggregation (Barker and Lloyd, 1997). Bibliometric analyses have also been used at the national level to provide comparisons between the publication and citation performance of the UK and other countries, both overall and in particular fields of science.

\section{The ESRC's evaluation portfolio}

The ESRC is the most advanced of the UK research councils in terms of research evaluation, although the others are becoming 'more serious' in their efforts. The EPSRC, for example, established a new framework for all its evaluation activities under the headings of quality, people and exploitation (QPE) during 1997 (Barker and Lloyd, 1997). ESRC has obviously felt greater governmental pressure than other research councils to justify the socioeconomic relevance of the research it funds. As the secretary of the ESRC evaluation committee commented to us, 'The Medical Research Council doesn't have to demonstrate impact, ESRC does.' The pressure through the 1980s was to establish the credibility of the research that was funded. This was achieved through accountability and by amassing 'ammunition' on the impact and outcomes of the research, such as described below.

ESRC has a separate Research Evaluation Committee of eight members, all but one external to the Council. The committee comprises researchers, academics, civil servants (including a member from the Audit Commission), and business representatives. Professor Arie Rip of The Netherlands is the sole non-UK-based member. The committee's evaluation activities are completely separate from the ESRC's granting processes. The committee reports only to Council, sets its own agenda and acts as independently as it can. All ESRC-funded research projects, programmes and centres undergo some form of post hoc assessment, the scale and format varying with the size and purpose of the grant (ESRC, 1996). The annual evaluation budget is relatively small - about $£ 100,000$ out of ESRC's $£ 65$ million budget. 


\section{The pressure through the 1980 s was to establish the credibility of the research that was funded by the ESRC. This was achieved through accountability and by amassing 'ammunition' on the impact and outcomes of the research}

Research project and programme evaluation. ESRC formally evaluates all two- to three-year project grants, of which the Council awards around 500 a year. A grant is typically $£ 100,000$, although this includes $46 \%$ on-costs for salary costs (the grants commonly fund postdoctoral researchers). There are three application rounds a year, with about 300 applications in each round. Each research project is evaluated on the basis of an 'end of award' report provided by the researcher. The 5,000-word report is due three months after the end of the award and covers the aims and objectives of the research and its outcomes - including publications, software and broader outcomes. Researchers may submit up to two draft or final publications with the report, but are not penalised if they do not. If the researcher fails to produce an end of award report the final grant payment is withheld.

The report is assessed usually by two to four independent peer 'rapporteurs' (more if there is disagreement) and given a grade on a four-point scale: Outstanding; Good; Problematic; and Unacceptable. The end of award reports are public documents, but the rapporteurs' evaluations are not. There is limited provision for appeal by the researcher against assessments in the lower two grades. It is difficult to say what weight is given to the formal assessment. At the margin the evaluation is probably influential, but only $2 \%$ of projects are graded 'unacceptable'.

In ESRC parlance, research programmes are networked groups of research projects under a single programme director. Programmes typically consist of 15 to 20 projects over four to five years, with a budget of $£ 3-4$ million. The objectives of the programme are set jointly by ESRC and the programme director. Each programme has an advisory committee. The projects comprising the programme are subject to the same post hoc evaluation as individual research projects, described above. In addition, every programme is also evaluated once the component project evaluations are complete, that is, after about six years. This allows for inclusion in the evaluation of any organised dissemination activities. Programmes produce an annual report, where the director may flag projects that are not working well, but this report is for management rather than evaluation purposes, going to the programme advisory committee rather than to the evaluation committee.

ESRC carries out around two or three programme reviews annually. The evaluation committee draws up an evaluation brief for each programme. The brief typically covers achievements in relation to overall aims and objectives; academic dissemination activities; a review of the interaction and impact on research users; research 'value added' contributed by the programme; contribution of the projects to the programme objectives; and the programme's potential contribution to future research developments. The evaluation task is let in an open process (usually advertised) to an external, independent evaluator - the review is never performed 'in-house'. The evaluator may be an individual academic, professional body (eg, the Royal Economics Society) or academic consultant groups like PREST (Sussex) and SPRU (Manchester). The evaluation is a two-stage process. First, the consultant reviews the project end of award reports, the rapporteurs' comments and project outputs, and the programme director's report. The consultant may also interview or survey the award holders about their experience with the programme. The reviewer will then survey (via questionnaire) putative non-academic users of the research. A programme evaluation report of around 10,000 words is submitted to the research evaluation committee and thence to the Council's Board.

Research centres and research training. The research centres are the ESRC's largest research grants, for a term of 10 to 15 years. The broad research objectives of centres are set by ESRC. A recent example is the Centre for Economic Performance. Centres undergo a mid-term review at five years. Their main evaluation, however, is carried out at eight years (for centres seeking funding beyond 10 years) and at 11 years for centres not bidding for continuation of funding. Again, the review is a two-stage process. The centre's report of its academic and non-academic achievements, and examples of publications and other outputs, are subject to peer review. A panel of expert academics and 'users' then assesses the report and the reviewers' comments. In the case of an applied economics centre, the panel included representatives from the Department of Trade and Industry, the Confederation of British Industry, the Trade Union Congress and several economic 'think tanks'. The panel usually makes a site visit of up to two days' duration. ESRC's Resources Board also provides funding for 'soft' and 'hard' infrastructure, such as for the development of data sets - a recent centre is in the field of the analysis of large data sets. In this case, the centre is evaluated in the same way as other research centres.

About one-third of ESRC's budget is devoted to research training. ESRC staff are keen to expand the evaluation of the Council's research training programmes. However, little capacity is available, and there is also a feeling that it would duplicate the examiners' job - at the individual level, 'the $\mathrm{PhD}$ is basically the evaluation'. Industry-linked awards (CASE scholarships) are more likely to be evaluated (though this has not yet occurred). There is no tracking of careers beyond first employment destination. 
Broader outcomes and impacts of research. Outcomes at the system level are aggregated from the project/programme/centre evaluations, together with 'success stories'. In relation to bibliometrics indicators, the ESRC view is that such analyses have severe limitations when applied to the social sciences because of different publication patterns, time lags and poor representation in the ISI database, particularly on 'domestic' research questions. Barker and Lloyd (1997) also comment that bibliometric analysis is regarded as unsuitable for economic and social research fields. In addition, very few patents emerge from ESRC-funded research.

ESRC has therefore concentrated on broader indicators of research outcomes and impact, notably through its Research Grants Archive and Database (REGARD) database. ESRC has contracted the Institute for Learning and Research Technology, Bristol University, to establish and maintain REGARD. The idea is to provide a publicly accessible record of a range of outputs and outcomes from research funded wholly or partially by ESRC, collected under 12 main headings including publications, and outcomes such as media appearances and academic honours (Table $3)$. Where research products are available on-line, REGARD provides a direct electronic link for the user. The principal award holders are surveyed after two to five years through a paper-based survey. However, they may submit information on research 'products' to the database website (through a moderator/cataloguer) at any time. The REGARD database - still experimental - is unique to ESRC. The other research councils do not match this collection, although the BBRC maintains a form of research outcomes database in association with the Wellcome Trust.

In recent years, ESRC has been developing a new approach to research impact assessment. While there is some theory on impact assessment in the social sciences there has been, in ESRC's view, no practical testing, and thus no appropriate 'off the peg' techniques. A contract for 'Assessing Research Impact on Non-academic Audiences' was let to SPRU in 1997. The brief noted that 'The Council wishes to develop its current evaluation system, which provides assessments of research quality and engagement with non-academic groups, to incorporate measures of impact on decision-making and understanding in the private, public, and voluntary sectors'. ESRC nominated 'networks and flows, user panels and tracing postresearch activity' (eg, career paths) as suggested methodologies.

Two research programmes have been chosen for a pilot study: the AIDS Programme (complete) and the Innovation Programme (current). The methodology involves mapping a range of interactions and networks, by asking academics how they interact with users (and vice versa) and by employing user panels (people who have not heard of the research programme). The outcome is expected to be a 'tool kit' that can be used by non-professional evaluators.
Table 3. Categories of research 'results' collected in the ESRC's REGARD product survey form

1. Book, pamphlet or other single published item (including non-print items like CD-ROMs, video or audio recording). Book chapter.

Paper to conference or seminar, etc. (published).

Article in journal or newspaper, etc.

Data-set.

Software or multimedia package.

Broadcast.

'Major' consultancy, advisory service or training course. Research facility (such as laboratory or production facility). Invention or product (patent or physical product).

11. Degree or other honour (academic or professional).
12. Other publication or product (published or publicly accessible).

Source: http://www.regard.ac.uk

The results must be affordable - to augment existing approaches - and generic enough to be transferable to other programmes.

\section{Conclusions}

Our limited review of recent British advances in the evaluation of university research outcomes points to some parallels with other countries studied in this volume as well as some differences. First, it underlines the strong primacy of peer-review panels for assessing the quality of most academic research as well as in 'merit review' - in the sense of relevance and value for money (Barker and Lloyd, 1997). More broadly, Hills and Dale (1995) comment that 'directly or indirectly, peer review dominates, though it does not monopolise, UK evaluation methodology'. The RAE in particular is a spectacular example of 'mass peer evaluation' that strongly drives research funding and institutional behaviour. There is perhaps less evidence than in countries like The Netherlands for the use of evaluation as a learning process that encourages the 'performance management' of university research.

Second, as elsewhere, we see some tension between criteria of excellence and socioeconomic benefit in valuing university research outcomes. The research councils are expected to use a broader range of criteria in their assessments than are used in the more publication-oriented RAE. Hills and Dale (1995) predicted that the importance of evaluation criteria measuring the 'impact' of research was likely to continue to increase in the UK, as was the involvement of potential or actual users in the evaluation process. This certainly seems to have occurred in recent years. The ESRC, for example, has reacted to these pressures through user panels and by supporting the development of methodologies for assessing the 'non-academic impact' of research. The Council has also pioneered a Web-based electronic system for collecting information on a broad range of outcomes of the research they fund. Potentially, at least, these data contribute to broader performance measures for the research council.

Lastly, research output evaluation is increasingly contributing to agency and national planning - 
witness the common performance indicators for the research councils - though not as obviously as in some countries like the USA where there is a legislative basis for performance measurement and reporting. It will be interesting to see to what extent broader S\&T planning mechanisms, such as the Technology Foresight programme and 'Forward Look' (UK Government, 1993), are able to strengthen and unify the already well-established mechanisms for the evaluation of university research outcomes funded through the 'dual support' channels in the UK.

\section{Acknowledgements}

We thank Paul Stocker (OST) and lain Jones (ESRC) for their assistance, and Linda Butler and Stuart Macdonald for their comments on the paper. Responsibility for the content and opinions herein is assumed by the authors.

\section{Note}

1. The six research councils are: biotechnology and biological sciences; medical, engineering and physical sciences; economic and social sciences, natural environment, particle physics and astronomy.

\section{References}

D Barker and P Lloyd (1997), 'Evaluation of Scientific Research in the United Kingdom', The Evaluation of Scientific Research: Selected Experiences, OCDE/GD(97)194, OECD, Paris, pages 47-58.

P Bourke (1997), Evaluating University Research: The British Research Assessment Exercise and Australian Practice, NBEET/ARC/HEC Commissioned Report No. 56, AGPS, Canberra.

Economic and Social Research Council, Evaluation Guide One: Evaluating End of Award Reports, April 1997; Evaluation Guide Two: Evaluating Research Programmes, July 1996; Evaluation Guide Three: Evaluating Research Centres, July 1996, ESRC, Swindon.

P V Hills and A J Dale (1995), 'Research and technology evaluation in the United Kingdom', Research Evaluation, 5(1), pages 35-44.

Report of the National Committee of Inquiry into Higher Education, Higher Education in the Learning Society, ('Dearing Report') (1997), HMSO, London.

UK Government (1993), Realising Our Potential - A Strategy for Science, Engineering and Technology, Cm 2250, HMSO, London. 